\title{
Microbial levels on street foods and food preparation surfaces in Mangaung Metropolitan Municipality
}

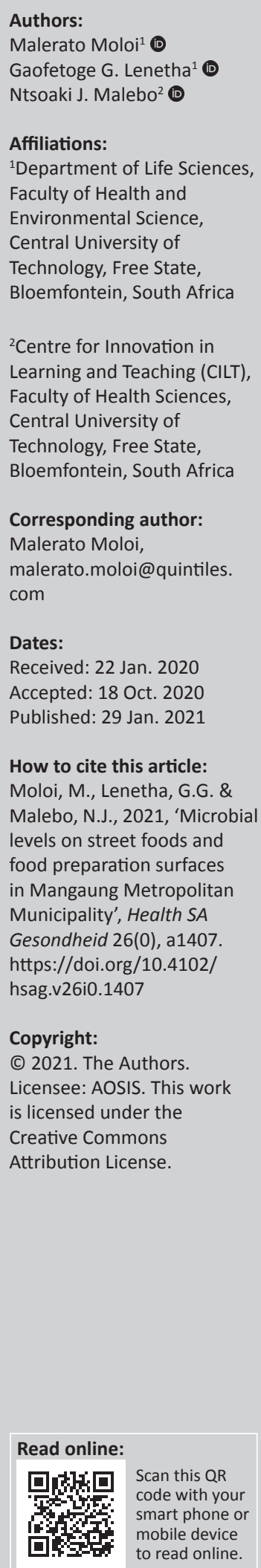

Background: The street food sector has become an important component of the food distribution system in many cities in both developing and industrialised countries, particularly for midday meals. However, certain street food can pose a significant risk to consumers because of microbiological contamination.

Aim: The aim of this study was to determine the microbial levels of street foods and preparation surfaces in Mangaung Metropolitan Municipality.

Setting: The study selected study setting was vending sites close to taxi ranks where prepared meals were accessible to consumers.

Methods: The study was conducted in Mangaung Metropolitan Municipality during the winter season. Samples were collected through convenience sampling from the representative towns Thaba Nchu, Botshabelo and Bloemfontein. Using swabs, surface samples were collected and quantified from selective media. Eight beef samples were also collected; the microbial load on each sample was quantified and identified using a RapID kit.

Results: The surface swabs obtained in Botshabelo $\left(1.1 \times 10^{4} \mathrm{cfu} / \mathrm{m}^{2}-1.1 \times 10^{6} \mathrm{cfu} / \mathrm{m}^{2}\right)$ showed higher microbial counts as compared to those obtained in Bloemfontein $\left(1.1 \times 10^{4} \mathrm{cfu} / \mathrm{m}^{2}-1.1 \times\right.$ $\left.10^{5} \mathrm{cfu} / \mathrm{m}^{2}\right)$ and Thaba Nchu $\left(1.1 \times 10^{4} \mathrm{cfu} / \mathrm{m}^{2}-1.1 \times 10^{5} \mathrm{cfu} / \mathrm{m}^{2}\right)$. Higher microbial counts were observed on meat samples sampled in Thaba Nchu (50 cfu $/ \mathrm{g} \times 10^{5} \mathrm{cfu} / \mathrm{g}$ ), Bloemfontein (48 $\mathrm{cfu} / \mathrm{g} \times 10^{4} \mathrm{cfu} / \mathrm{g}$ ) and Botshabelo $\left(33 \mathrm{cfu} / \mathrm{g} \times 10^{5} \mathrm{cfu} / \mathrm{g}\right.$ ) when compared to international microbiological standards. After assessing the microbial levels, Staphylococcus aureus, Escherichia coli, Candida guilliermondii, Corynebacterium jeikeium, Psychrobacter phenylpyruvicus and Peptostreptococcus tetradius were identified.

Conclusion: This study confirmed contamination of surfaces and food served by vendors in Mangaung Metropolitan Municipality. The identified foodborne bacteria could pose a public health problem in each specific locality.

Keywords: foodborne microorganisms; microbial contamination; street foods; surface swabs; food safety.

\section{Introduction}

According to the United Nations Food and Agricultural Organisation (FAO), about 2.5 billion people consume street food every day (Da Silva et al. 2014). Therefore, the demand to ensure the supply of safe food has been one of the major challenges and concerns for producers, consumers and public health officials globally (Da Silva et al. 2014). This is because foods excessively contaminated with pathogenic and spoilage microorganisms are undesirable and can cause foodborne illnesses (Hertanto et al. 2018). Transmission of pathogenic microorganisms to food takes place through poorly washed hands and dirty clothing, such as aprons that are worn during the preparation and serving of food (Hertanto et al. 2018). In addition, contaminated foods can endanger public health by causing various acute and chronic foodborne illness through pathogenic microbes or toxic substances present in them (Nazni \& Jaganathan 2014).

Foodborne illness, also called 'foodborne disease', 'foodborne infection' or 'food poisoning', is a common, costly but preventable public health problem (Akter 2016). Foodborne illness can be caused by bacteria, parasites, toxins and viruses. Amongst the common pathogens are Salmonella and Escherichia coli, which account for 52000 and 37000 deaths, respectively, each year (WHO 2015). Each year, reports indicate that one in six Americans gets sick by consuming contaminated foods or beverages (Akter 2016). In South Africa, a progressive increase in listeriosis cases was noted starting in mid-June 2017, heralding what was to become the world's largest listeriosis 
outbreak. A total of 1060 cases were reported for the period of 01 January 2017 - 17 July 2018 (Smith et al. 2019). Different disease-causing microbes, or pathogens, can contaminate foods. In addition, poisonous chemicals, or other harmful substances, can cause foodborne illness if they are present in food (Akter 2016).

The global burden of foodborne illness states that each year as many as 600 million, or almost 1 in 10 people in the world, fall ill after consuming food and water contaminated with viable pathogenic bacterial cells (or spores in the case of botulism) or food containing toxins produced by toxigenic bacteria and moulds (Akter 2016). Of these, 420000 people die, including 125000 children under the age of 5 years. Foodborne illnesses have devastating health implications, such as kidney and liver failure, brain and neural disorders, reactive arthritis and cancer, with fatal results (WHO 1996). Although acute gastrointestinal diseases are not all foodborne and foodborne illness does not always result in acute gastroenteritis, food does represent an important vehicle for pathogens causing acute gastroenteritis (Lamin-Boima 2017). Previous research done to assess the quality of street food in several countries has demonstrated that street food was the positive cause of foodborne illnesses (WHO 2010).

The statistics available in South Africa for the period 2001-2006 show that most epidemics were reported in the provinces of Eastern Cape, KwaZulu-Natal and Limpopo (DoH 2006). According to Shonhiwa et al. (2019), 327 foodborne illness outbreaks were reported from January 2013 to December 2017, causing illness in 11155 individuals, with 78\% hospital visits, $4 \%$ hospital admissions and $0.4 \%$ deaths. Most of the outbreaks were reported in the warmer months, from KwaZulu-Natal (43\%), Gauteng (19\%) and Mpumalanga (12\%) provinces. Institutional outbreaks were most common (32\%), followed by household outbreaks (27\%) and community outbreaks (11\%). However, Motarjemi (2013) believes that the majority of foodborne illness could be averted if food handlers were knowledgeable in safe food handling and if customers were informed correctly in their choices of food and food handling.

In Mangaung Metropolitan Municipality, many consumers buy street food daily, as it is both available and affordable. However, the microbial levels of these foods and their safety for human health are not well known. Knowing the bacteriological quality of street foods is an important factor in recognising the safety problems related to street foods (Amare et al. 2019). In the Mangaung metro area, street vendors are regulated by Mangaung Local Municipality bylaws relating to street trading as promulgated by Local Government Notice no. 4 of 20 January 2006 to ensure the safety of food. Therefore, this study seeks to investigate the microbial level of street food in the Mangaung metro area.

\section{Materials and methods Study area selection}

Microbial samples were collected through non-probability convenience sampling in the Mangaung metro area in Free
State, South Africa. The sampling method was chosen to conveniently select businesses that primarily sold cooked meat. Eight whole samples of cooked beef were randomly collected with dry and sterile polythene bags from different vendor stalls at different taxi ranks in Botshabelo, Thaba Nchu and Bloemfontein Central Business District. In addition, sterile surface swabs were used to collect samples from the preparation surfaces selected on the vending stalls, namely, food preparation areas and meat preparation areas. The samples were collected between 11:00 and 14:00, which is the usual holding period of the food. Afterwards, the samples were kept on ice during transportation to the laboratory. Then, the samples were placed in a refrigerator and analysed without delay. To assess factors that may contribute to the contamination of foods and surfaces, a checklist was used.

\section{Microbial quantification}

For microbial quantification from meat samples, the beef samples were blended using a sterile blender, and then $10 \mathrm{~g}$ of beef samples were mixed with $90 \mathrm{~mL}$ of sterile peptone water and homogenised to make a 1:10 dilution. The surface swabs were also mixed with $90 \mathrm{~mL}$ of sterile peptone water and homogenised appropriately. Next, serial dilutions were done, the dilutions were prepared up to $10^{6}$ dilution, using a spiral plater. A spiral plater is an instrument used to dispense a liquid sample onto the Petri dish in a spiral pattern. The purpose of this method is to inoculate several dilution factors onto a single Petri dish. This allows a significant reduction in the number of dilutions performed and dishes used. About 1 $\mathrm{mL}$ of all dilutions was plated in triplicate Petri dishes using plate count agar (PCA). The plates were then incubated at $37{ }^{\circ} \mathrm{C}$ for $24 \mathrm{~h}$. In addition, selective media were also used. Baird Parker was used for isolation of Staphylococcus species, mannitol egg yolk polymyxin (MYP) agar was used for isolation of Bacillus species and xylose lysine deoxycholate (XLD) agar was used for isolation of Salmonella species. After the appropriate incubation period, the plates were then examined for microbial growth (Sanders 2012).

\section{Microbial identification}

The species of the foodborne pathogens were identified using a RapID identification kit (Thermo Fisher Scientific, SA). Briefly, organisms were streaked onto Petri dishes for isolation of pure cultures and used the next day. Afterwards, colonies were scraped from the agar plates using an inoculation loop into the RapID inoculation fluid to achieve the visual turbidity of a 2 McFarland standard. Next, the suspension was mixed thoroughly using the vortex. The contents of the suspension were then transferred to the RapID panel using a pipette. The test suspension was later mixed with the reaction cavities found in the RapID panel. Afterwards, the inoculated panels were incubated at $35^{\circ} \mathrm{C}$ to $37^{\circ} \mathrm{C}$ for $4 \mathrm{~h}$. Following the incubation, two drops of RapID ONE reagent were added to cavities 15, 16 and 17. In additional, two drops of RapID spot indole reagent were added to Cavity 18. The cavities were then observed for 
colour development. The results of the colour development were recorded using the colour guide sheet and report form provided with the RapID kit. The results were recorded by scoring the colour development using either a plus or minus sign to indicate positive or negative reactions. The observed colour changes were a result of biochemical reactions. The numerical microbe code was then derived from the scores. These microbe codes were entered in the ERIC software for identification of the organism (Thermo Scientific SA).

\section{Ethical considerations}

The study was approved by the Faculty Research and Innovation Committee. Ethical clearance was not needed in the current study as samples were collected from surfaced. Consent was requested from all vendors where samples were collected.

\section{Results and discussion}

Based on the results found in the current study, Figure 1 represents the bacterial counts from meat samples collected from Mangaung metro area street vendors. The microbial levels of the meat samples grown on PCA medium are shown as dilutions from $1.1 \times 10^{4} \mathrm{cfu} / \mathrm{g}$ to $1.1 \times 10^{6} \mathrm{cfu} / \mathrm{g}$. Bacterial counts obtained in Thaba Nchu $\left(\leq 50 \mathrm{cfu} / \mathrm{g} \times 10^{5} \mathrm{cfu} / \mathrm{g}\right)$, Bloemfontein $\left(\leq 48 \mathrm{cfu} / \mathrm{g} \times 10^{5} \mathrm{cfu} / \mathrm{g}\right)$ and Botshabelo $\left(\leq 33 \mathrm{cfu} / \mathrm{g} \times 10^{5} \mathrm{cfu} / \mathrm{g}\right)$. These results are higher when compared to the regulations governing microbiological standards for foodstuffs and related matters in South Africa, which stipulate that no person should sell meat for which the total colony count of organisms exceeds 10000 per gram.

These high microbial counts are concerning, as they are an indication that proper food handling and preparation techniques are not always practised by food handlers. Common causes of food poisoning include failing to wash hands completely before preparing or eating food; using utensils, cutting boards or serving dishes that are not clean, causing cross-contamination; consuming dairy products or food containing mayonnaise that have been left out too long; and consuming foods that have not been stored or cooked at the right temperature, especially meat and poultry (Pietrangelo 2015). Infections caused by microorganisms are largely the result of the poor hygiene of the person responsible

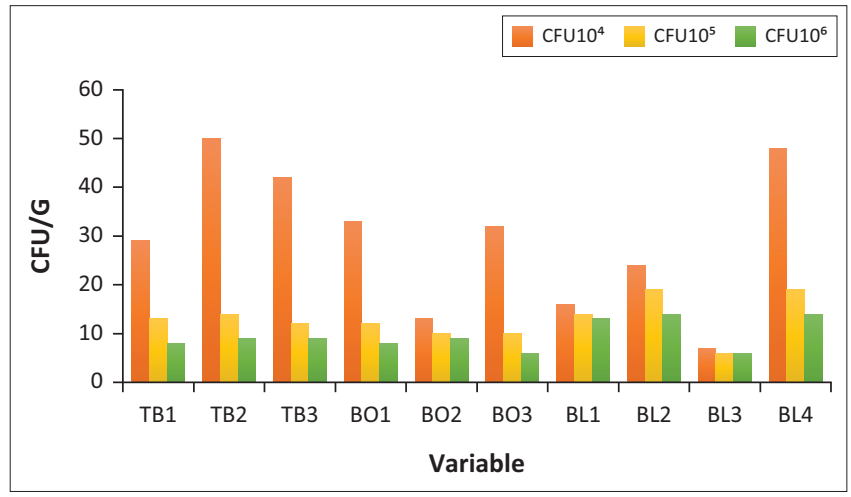

TB, Thaba Nchu; BO, Botshabelo; BL, Bloemfontein; CFU, colony-forming units. FIGURE 1: Total viable counts isolated from meat samples. for preparing the food (Uçar, Yilmaz \& Cakiroglu 2016). In addition, lack of good hygiene practices by food handlers has been reported to influence microbial rates and could also place consumers at risk of contracting foodborne illnesses, which may increase the statistical rates of deaths (Setlhare 2013). Okojie and Isah (2014) reported that street foods, when prepared in very dirty surroundings with wastewater and garbage disposed of nearby, provide nutrients and a breeding ground for rodents and other pests that could cause contamination of the food. Similar results were found in this study. During the survey, using a checklist to determine the status of the vending sites, it was observed from our results that most of these vending sites lacked basic infrastructure and services such as potable running water and waste disposal facilities; hand and dish washing water was usually insufficient and often reused. In most cases during the survey, running water was not available at vending sites; washing of hands and crockery was done in bowls or buckets and sometimes without soap. Furthermore, access to a frequent water supply was limited to facilities that had tap water. All these were considered violations of the regulations governing the general hygiene requirements for food premises and the transport of food and highlight a need for continuous monitoring of these businesses by environmental health professionals.

The regulations governing the general hygiene requirements for food premises and the transport of food (DOH 2002) stipulate that wash basins should always be provided, together with an adequate supply of soap and disposable paper towels. Therefore, street food vending stalls should have potable water available around the stall to make it easy for the vendors to access water. Note that most stalls are erected by vendors, with some erected by government in certain areas; this recommendation could work in areas where stalls have been erected by government or where stalls are erected close to business areas such as taxi ranks. The regulations also stipulate that no person should handle food intended for consumption if the hands of this person are not washed with soap and water. The lack of basic infrastructure to support the practice of hand washing was a matter of concern. This highlights a possible lack of compliance with proper hygiene practice and implies that the implementation of basic hygiene practices may be difficult because of the lack of hygiene infrastructure.

Microbial counts from meat samples at Bloemfontein, Thaba Nchu and Botshabelo (Figure 1) were found to be higher when compared to the regulations governing microbiological standards for foodstuffs and related matters in South Africa, which stipulate that no person should sell meat for which the total colony count of organisms exceeds 10000 per gram.The results also showed the presence of Staphylococcus isolates (Figure 2), indicating that improper food handling practices, handling food with bare hands, reusing surfaces without cleaning first and not wearing aprons contributed to the presence of these foodborne pathogens. S. aureus is conveyed to food by the person handling it. Persons with skin, nose or 
throat infections or inflammatory wounds pass this microorganism onto the food (Uçar et al. 2016). The foods posing a particular risk for contamination with Staphylococcus spp. include cooked meat, potato salad, desserts with milk, such as custard, and chicken, fish and other meat salads (Duyff 2012). It is important to realise that food vendors can be carriers of pathogens such as E. coli, S. aureus and Salmonella, Shigella and Campylobacter spp. The food vendors eventually transfer these foodborne microbes to the consumers (Siddiqua 2016). Transfer can be direct, from person to person; indirectly in two stages, from person to

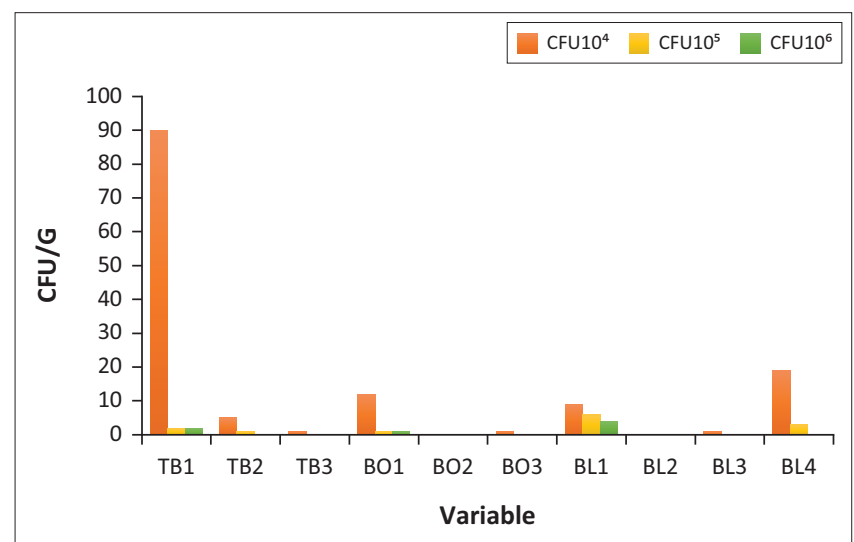

TB, Thaba Nchu; BO, Botshabelo; BL, Bloemfontein; CFU, colony-forming units. FIGURE 2: Total viable counts from meat samples for Staphylococcus isolates.

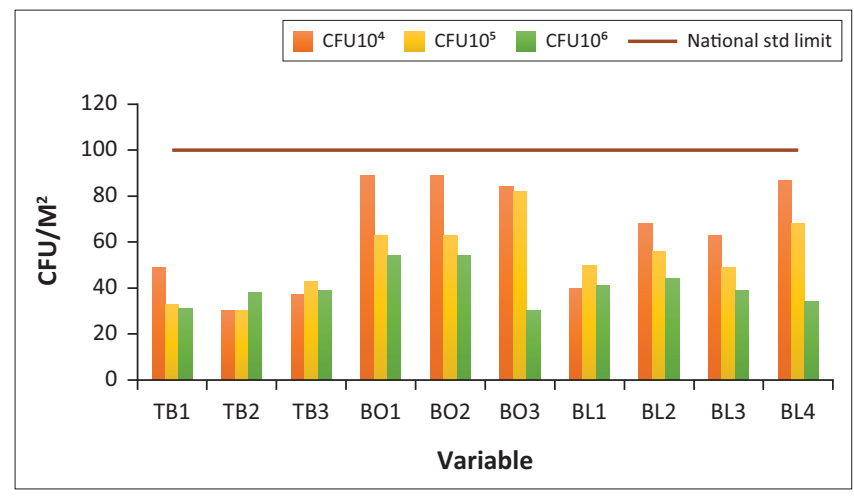

TB, Thaba Nchu; BO, Botshabelo; BL, Bloemfontein; CFU, colony-forming units; std, standard FIGURE 3: Total viable counts from preparation surfaces, collected using microbial swabs. contact surface and from contact surface to person; and indirectly from person to food and from food to person (Todd et al. 2007). Moreover, a lack of adequate infrastructure can affect the implementation of good hygiene practices.

Figure 3 illustrates the total viable counts recorded on food preparation surfaces at various vending stalls in Thaba Nchu, Bloemfontein and Botshabelo. The samples obtained in Botshabelo $\left(1.1 \times 10^{4} \mathrm{cfu} / \mathrm{m}^{2}-1.1 \times 10^{6} \mathrm{cfu} / \mathrm{m}^{2}\right)$ showed a higher microbial count compared to those of Bloemfontein $\left(1.1 \times 10^{4}-1.1 \times 10^{5} \mathrm{cfu} / \mathrm{m}^{2}\right)$ and Thaba Nchu $\left(1.1 \times 10^{4} \mathrm{cfu} / \mathrm{m}^{2}-\right.$ $\left.1.1 \times 10^{5} \mathrm{cfu} / \mathrm{m}^{2}\right)$. This may be attributed to the fact that the vending stalls in Botshabelo are not next to paved roads, as opposed to those in Thaba Nchu and Bloemfontein. The vending stalls were not covered, and there was also dust from construction vehicles working not far from the stalls in Botshabelo. Even though the surface swab results from Botshabelo are a cause for concern, the counts were found to be lower than the South African national standard $\left(100 \mathrm{cfu} / \mathrm{m}^{2}\right)$.

After quantifying the microbial levels, the RapID identification method was used to identify foodborne pathogens that might be present in meat samples at the selected areas of Mangaung Metropolitan Municipality. The RapID results obtained (Table 1) indicate the presence of Candida guilliermondii, which is a yeast, and the bacteria Corynebacterium jeikeium, Psychrobacter phenylpyruvicus and Peptostreptococcus tetradius, amongst others. All these bacteria are found on human skin and might have been transferred from the hands of food handlers to the meat because none of the food handlers were seen wearing gloves during the food preparation and serving (Table 1). Such a food handler may have contaminated his or her hands when using the toilet and not washing hands, or bacteria might have spread from raw meat to green salads via the hands of the food handler (Kariuki 2018).

Staphylococcus aureus was also identified on the meat samples of the three selected areas (Thaba Nchu, Botshabelo and Bloemfontein). The presence of S. aureus found in meat samples highlights the need for providing

TABLE 1: Characterisation of foodborne pathogens isolated from meat samples.

\begin{tabular}{|c|c|c|c|c|}
\hline Origin and sample no. & Species identified using RapID & Source & Health effects & Reference \\
\hline Thaba Nchu 1 & Prevotella bivia & Vaginal tract, oral flora & $\begin{array}{l}\text { Endometritis and pelvic } \\
\text { inflammatory disease }\end{array}$ & Mirza et al. 2012 \\
\hline Thaba Nchu 1 & Escherichia coli & $\begin{array}{l}\text { Undercooked or raw food, unpasteurised milk, } \\
\text { apple juice, contaminated water }\end{array}$ & $\begin{array}{l}\text { Bloodstream infection and } \\
\text { urinary tract }\end{array}$ & CDC 2011 \\
\hline Thaba Nchu 1 & Psychrobacter phenylpyruvicus & Human skin & Surgical wound infection & Deschaght et al. 2012 \\
\hline Thaba Nchu 2 & Corynebacterium jeikeium & Human skin & $\begin{array}{l}\text { Infection after disruption of the } \\
\text { skin by surgery (cardiac or } \\
\text { orthopaedic surgery) }\end{array}$ & Bechara et al. 2011 \\
\hline Botshabelo 1 & Escherichia hermannii & Chickens and humans (blood, urine) & Bloody diarrhoea & Sedlock et al. 2018 \\
\hline Botshabelo 1 & Yersinia kristensenii & Soil, freshwater, food & Human enteritis & - \\
\hline Botshabelo 2 Botshabelo 3 & Peptostreptococcus tetradius & Human skin & Clinical infection & Song et al. 2003 \\
\hline $\begin{array}{l}\text { Bloemfontein } 1 \\
\text { Bloemfontein } 2\end{array}$ & Candida guilliermondii & Human skin and mucosal surfaces & $\begin{array}{l}\text { Chronic onychomycosis, septic } \\
\text { arthritis and endocarditis }\end{array}$ & Girmenia et al. 2006 \\
\hline Thaba Nchu 3 & Staphylococcus aureus & The exterior of a human ear and animals & $\begin{array}{l}\text { Human skin infections, } \\
\text { sialadenitis and food poisoning }\end{array}$ & Madigan \& Martinko 2005 \\
\hline $\begin{array}{l}\text { Thaba Nchu } 2 \\
\text { Botshabelo } 2\end{array}$ & Shigella spp. & $\begin{array}{l}\text { Salads (potato, tuna, chicken), raw vegetables, } \\
\text { milk and dairy products, poultry }\end{array}$ & $\begin{array}{l}\text { Blood or mucus in the stool, } \\
\text { possible fever }\end{array}$ & Ghosh et al. 2007 \\
\hline
\end{tabular}


food handlers with educational training with respect to proper hygiene practices because humans are possible sources of the bacteria, as well as the need for provision of hand washing tools. Improper food hygiene practices are worrying, as S. aureus causes food poisoning with changes in blood pressure and pulse rate (Setlhare 2013). Staphylococcal disease results from eating food contaminated with toxins such as enterotoxin-producing strains of S. aureus, which leads to diarrhoea and vomiting. Staphylococci grow in food, in which they produce their toxins. Thus, staphylococcal food poisoning does not result from ingesting the bacteria but rather from ingesting the toxins that are already present in the contaminated food.

The results obtained (Table 1) also indicate the presence of $E$. coli in meat samples isolated from Thaba Nchu. This is a cause for concern because the presence of E. coli in food usually indicates recent faecal contamination (Kariuki 2018). Faecal coliforms appear in great quantities in the intestines and faeces of people and animals; hence, their presence in a food sample often indicates recent faecal contamination, meaning that there is a greater risk that pathogens may be present (Kariuki 2018). Escherichia coli has also been associated with contaminated water (CDC 2011). In addition, the water used by street vendors is not filtered; that is why it may contain bacteria and microorganisms such as E. coli. Moreover, E. coli might have been present in the contaminated water used by the food handlers, because they reuse water repeatedly, even when it is no longer clean to use it. This practice occurs because of the limited availability of hand washing infrastructure, which includes running water and basins for hand washing.

In addition to E. coli, Shigella spp. were isolated from the meat from both Thaba Nchu and Botshabelo (Table 1). According to the literature, Shigella spp. are frequently found in water polluted with human faeces (Dilbaghi \& Sharma 2007). They can easily multiply at temperatures between $10^{\circ} \mathrm{C}$ and $48^{\circ} \mathrm{C}$ (Baş, Yüksel \& Çavuşoğlu 2017). The optimum growth temperature for this bacterium is $37^{\circ} \mathrm{C}$ (Warren, Yuk \& Schneider 2007). Contamination of these foods usually takes place through the faecal-oral route. Faecally contaminated water and unsanitary handling by food handlers are the most common causes of contamination (Dilbaghi \& Sharma 2007). In addition, improper waste disposal has been associated with the transmission of enteric pathogens like Salmonella spp., Shigella spp. and E. coli. Generally, vendors in informal settings do not have waste bins around the stalls; they use boxes and plastics to collect waste, and place these waste-collecting materials near the vending stalls. The presence of Shigella spp. might have resulted from the waste that was observed around the stalls. The most important protective factor against Shigella spp. is following proper personal hygiene rules (Uçar et al. 2016). Hand washing before handling food and thoroughly cooking all food before eating decrease the risk of getting shigellosis (Ram et al. 2008).
Prevotella bivia, which is found in the vaginal tract, was also isolated from the meat sample from Thaba Nchu. This finding is an indication that the food handlers do not wash their hands after using the toilet. They all (100\%) indicated that the toilets were very far from their stalls, and that they must pay every time they use the toilets. These findings are consistent with a study conducted in Dhaka by Siddiqua (2016), where toilets were not available nearby in several cases, thus forcing vendors to eliminate their body wastes in nearby areas and return to their vending sites without washing their hands. In addition, in the current study, there was no potable water supply near the vending stalls; the food vendors obtained water from the nearby stores. The vendors stated that they only used the water for dish washing and cooking. During the survey, it was also observed that the vendors reused the dish washing water more than two times because they were trying to save the little water that they had.

Based on these results, Mangaung Metropolitan Municipality is urged to intervene and assist food handlers with the lack of basic infrastructure they are currently facing. This will be one of the keys to preventing cross-contamination and foodborne pathogens, which might lead to foodborne illnesses in the Mangaung metro area.

\section{Conclusion}

The meat obtained in Thaba Nchu, Bloemfontein and Botshabelo showed high microbial counts. These results are alarming when compared to the regulations governing microbiological standards for foodstuffs and related matters in South Africa, which stipulate that no person should sell meat for which the total colony count of organisms exceeds 10000 per gram. The results also showed the growth of $S$. aureus, indicating that the improper food handling practices carried out by food handlers contribute to the presence of these foodborne pathogens. The presence of pathogenic organisms such as E. coli is a cause for concern as it usually indicates recent faecal contamination. Therefore, consumption of such contaminated street vended foods poses a serious problem to community health.

In the current study, Table 1 shows that most of the bacteria identified are usually from the human skin and hair; the results may be an indication that the vendors are not practising food safety measures and hygiene, as transfer from the skin and hair can occur through touching surfaces and lack of hand washing when handling food. Consequently, vendors need to undergo food safety training to limit the spread of microbes through touching. Moreover, the lack of basic infrastructure (including nearby toilets) and services, such as potable running water and waste disposal facilities, as well as hand and dish washing water that is usually insufficient and often reused by food handlers, play an important role in the presence of foodborne pathogens identified in this study. Even though the surface swab counts were found to be lower than the South African national standard $\left(100 \mathrm{cfu} / \mathrm{m}^{2}\right)$, they are still cause for concern because 
they indicate that the food preparation surfaces are not being properly cleaned by food handlers

\section{Limitations}

No swabs were taken of the food handlers' hands.

\section{Acknowledgements}

The work is based on the research supported by the Central University of Technology, Free State institutional Innovation Fund. The National Research Foundation (Thuthuka grant ID: 117779) is also acknowledge for supporting aspects of this study.

\section{Competing interests}

The authors declare that they have no financial or personal relationship(s) that may have inappropriately influenced them in writing this article.

\section{Authors' contributions}

G.G.L., M.M. and N.J.M. were responsible for the conceptualisation, data curation from the literature and writing the initial and final draft. They were also responsible for the funding acquisition and critically review of the writing.

\section{Funding information}

This research received no specific grant from any funding agency.

\section{Data availability statement}

Data sharing is not applicable to this article as no new data were created or analysed in this study.

\section{Disclaimer}

The views and opinions expressed in this article are those of the authors and do not necessarily reflect the official policy or position of any affiliated agency of the authors.

\section{References}

Akter, N., 2016, 'Study on bacteriological quality of street vended foods collected from different private universities in Dhaka City, Bangladesh', Doctoral dissertation, EastWest University, viewed 30 November 2020, from https://www.semanticscholar. org/paper/Study-on-Bacteriological-Quality-of-Street-vended-Akter/ eaa7cebce4d2170a5b1b7ba7b65711502c22f8fb.

Amare, A., Worku, T., Ashagirie, B., Adugna, M., Getaneh, A. \& Dagnew, M., 2019 'Bacteriological profile, antimicrobial susceptibility patterns of the isolates among street vended foods and hygienic practice of vendors in Gondar town, Northwest Ethiopia: A cross-sectional study', BMC Microbiology 19(1), 120. https://doi. org/10.1186/s12866-019-1509-4

Baş, M., Yüksel, M. \& Çavuşoğlu, T., 2007, 'Difficulties and barriers for the implementing of HACCP and food safety systems in food businesses in Turkey', Food Control 18(2), 124-130. https://doi.org/10.1016/j.foodcont.2005.09.002

Bechara, C., Gousseff, M., Passeron, A., Podglajen, I., Day, N., Pouchot, J. et al., 2011 'Corynebacterium jeikeium pacemaker infection associated with antineutrophil cytoplasmic antibodies: A single positive blood culture could be sufficient for diagnosis', Journal of Medical Microbiology 60(2), 249-251. https://doi org/10.1099/jmm.0.023283-0

Centres for Disease Control and Prevention (CDC), 2011, Foodborne infections, viewed 15 November 2019, from https://www.cdc.gov/foodborneburden/index.html.
Da Silva, S.A., Cardoso, R.D.C.V., Góes, J.Â.W., Santos, J.N., Ramos, F.P., De Jesus, R.B. et al., 2014, 'Street food on the coast of Salvador, Bahia, Brazil: A study from the socioeconomic and food safety perspectives', Food Control 40, 78-84. https://doi. org/10.1016/j.foodcont.2013.11.022

Department of Health, 2002, Regulations governing general hygiene requirements for food premises the transport of food and related matters, viewed 16 October 2020, from http://www.health.gov.za/index.php/gf-tb-program/401-regulationsgoverning-general-hygiene-requirements-for-food-premises-the-transport-ofgoverning-general-hygiene-requirements-
food-and-related-matters-r638-of-2018.

Department of Health, 2006, Statistical notes, viewed 05 September 2018, from www. doh.gov.za/facts/stats-notes/2006/fpoisoning.pdf.

Deschaght, P., Janssens, M., Vaneechoutte, M. \& Wauters, G., 2012, 'Psychrobacter isolates of human origin, other than Psychrobacter phenylpyruvicus, are predominantly Psychrobacter faecalis and Psychrobacter pulmonis, with emended description of P. faecalis', International Journal of Systematic and Evolutionary Mmicrobiology 62(3), 671-674. https://doi.org/10.1099/ijs.0.032631-0

Dilbaghi, N. \& Sharma, S., 2007, Food spoilage, food infections and intoxications caused by microorganisms and methods for their detection, viewed 22 November 2019, from http://nsdl.niscair.res.in/bitstream/123456789/386/2/ FoodSpoilage.pdf.

Duyff, R.L., 2012, American dietetic association complete food and nutrition guide, p. 320, Houghton Mifflin Harcourt, Boston, MA.

Ghosh, M., Wahi, S., Kumar, M. \& Ganguli, A., 2007, 'Prevalence of enterotoxigenic Staphylococcus aureus and Shigella spp. in some raw street vended Indian foods' International Journal of Environmental Health Research 17(2), 151-156. https:// doi.org/10.1080/09603120701219204

Girmenia, C., Pizzarelli, G., Cristini, F., Barchiesi, F., Spreghini, E., Scalise, G. et al., 2006 'Candida guilliermondii fungemia in patients with hematologic malignancies', Journal of Clinical Microbiology 44(7), 2458-2464. https://doi.org/10.1128/ JCM.00356-06

Hertanto, B.S., Nurmalasari, C.D.A., Nuhriawangsa, A.M.P., Cahyadi, M. \& Kartikasari, L.R., 2018, January, 'The physical and microbiological quality of chicken meat in the different type of enterprise poultry slaughterhouse: A case study in Karanganyar District', IOP Conference Series: Earth and Environmental Science 102(1), 12-51. https://doi.org/10.1088/1755-1315/102/1/012051

Kariuki, E.N., 2018. 'Bacteriological safety of street foods and factors associated with food contamination among street food vendors in Githurai and Gikomba markets in Nairobi Kenya', Doctoral dissertation, Jomo Kenyatta University of Agriculture and Technology, pp. 1-67.

Lamin-Boima, P.T., 2017, 'Knowledge, attitude and practice of street food vendors in selected schools within Bo City Southern Sierra Leone', International Journal of Scientific and Technology Research 6(12), 254-259.

Madigan, M.T. \& Martinko, J., 2005, Brock biology of microorganisms, 11th edn., p. 5, Pearson Prentice Hall, Upper Saddle River, NJ.

Mirza, A., Bove, J.J., Litwa, J. \& Appelbe, G., 2012, 'Mixed infections of the Paronychium with Prevotella bivia', Journal of Hand and Microsurgery 4(2), 77-80. https://doi. org/10.1007/s12593-011-0054-7

Motarjemi, Y., 2013, Encyclopaedia of food safety, pp. 215-216, Academic Press, Cambridge, MA.

Nazni, P. \& Jaganathan, A., 2014, 'Study on microbial analysis of street-vended food samples sold in Salem District', International Journal of Research in Biological Sciences 4(3), 75-78.

Okojie, P.W. \& Isah, E.C., 2014, 'Sanitary conditions of food vending sites and food handling practices of street food vendors in Benin City, Nigeria: Implication for food hygiene and safety', Journal of Environmental and Public Health 2014, article 701316, 1-6. https://doi.org/10.1155/2014/701316

Pietrangelo, A., 2015, E. coli infection, viewed 30 November 2020, from https://www. healthline.com/health/e-coli-infection.

Ram, P.K., Crump, J.A., Gupta, S.K., Miller, M.A. \& Mintz, E.D., 2008, 'Part II: Analysis of data gaps pertaining to Shigella infections in low and medium human developmen index countries, 1984-2005', Epidemiology \& Infection 136(5), 577-603. https:// doi.org/10.1017/S0950268807009351

Sanders, E.R., 2012, 'Aseptic laboratory techniques: Plating methods', JoVE (Journal of Visualized Experiments) 63, e3064. https://doi.org/10.3791/3064

Sedlock, C., Tokarczyk, M., Sternlieb, M. \& Flomenberg, P., 2018, 'PICC-associated infection with Escherichia hermannii: A case report and review of the literature', IDCases 13, e00444. https://doi.org/10.1016/j.idcr.2018.e00444

Setlhare, G.G., 2013, 'Assessment of aerosolised microbiota in the food preparation area and selected wards at a typical district hospital in South Africa', Masters dissertation, Central University of Technology, Free State, Bloemfontein.

Shonhiwa, A.M., Ntshoe, G., Essel, V., Thomas, J. \& McCarthy, K., 2019, 'A review of foodborne diseases outbreaks reported to the outbreak response unit, National Institute for communicable diseases, South Africa, 2013-2017', International Institute for communicable diseases, South Africa, 2013-2017', International
Journal of Infectious Diseases 79(Suppl. 1), 73. https://doi.org/10.1016/j. ijid.2018.11.186

Siddiqua, S., 2016, 'Microbial profile testing of ready-to-eat street vended foods collected from different university premises', Doctoral dissertation, East-West University, viewed 30 November 2020, from https:/www.semanticscholar.org/ University, viewed 30 November 2020, from https://www.semanticscholar.org/
paper/Microbial-Profile-Testing-of-Ready-to-eat-Street-Siddiqua/ ee5960d622175950989465ff6250a73c9183f007.

Smith, A.M., Tau, N.P., Smouse, S.L., Allam, M., Ismail, A., Ramalwa, N.R. et al., 2019 'The outbreak of Listeria monocytogenes in South Africa, 2017-2018: Laboratory activities and experiences associated with whole-genome sequencing analysis of
isolates', Foodborne Pathogens and Disease 16(7), 524-530. https://doi.org/ 10.1089/fpd.2018.2586 
Song, Y., Liu, C., McTeague, M., Vu, A., Liu, J.Y. \& Finegold, S.M., 2003, 'Rapid identification of gram-positive anaerobic coccal species originally classified in the genus Pepto streptococcus by multiplex PCR assays using genus-and speciesspecific primers', Microbiology 149(7), 1719-1727. https://doi.org/10.1099/ specific prime
mic. $0.26227-0$

Todd, E.C., Greig, J.D., Bartleson, C.A. \& Michaels, B.S., 2007, 'Outbreaks where food workers have been implicated in the spread of foodborne disease, Part 3 Factors contributing to outbreaks and description of outbreak categories', Journal of Food Protection 70(9), 2199-2217. https://doi.org/10.4315/0362$028 \mathrm{X}-70.9 .2199$

Uçar, A., Yilmaz, M.V. \& Cakiroglu, F.P., 2016, 'Food safety-problems and solutions', in H. Makun (ed.), Significance, prevention and control of food related diseases, pp. $3-15$, IntechOpen, London.
Warren, B.R., Yuk, H.G. \& Schneider, K.R., 2007, 'Survival of Shigella sonnei on smooth tomato surfaces, in potato salad and in raw ground beef' International Journal of Food Microbiology 116(3), 400-404. https://doi.org/10.1016/j.ijfoodmicro.2007.02.010

World Health Organization, 1996, Essential safety requirements for street vended foods, World Health Organization, Geneva.

World Health Organisation, 2010, Ten facts on food safety, World Health Organization, Geneva.

World Health Organisation, 2015, WHO's first ever global estimates of foodborne diseases find children under 5 account for almost one third of deaths, viewed 21 January 2020, from https://www.who.int/news/item/03-12-2015-who-s-firstever-global-estimates-of-foodborne-diseases-find-children-under-5-account-foralmost-one-third-of-deaths. 